\title{
The Application of Right of Information Network Dissemination in SaaS Mode of Cloud Computing
}

\author{
Guo Peng \\ JiNan University Law School \\ Guangzhou China
}

\begin{abstract}
This paper presents that, in the SaaS mode, a cloud service provider can upload application software to "cloud" (Computer remote server of a cloud service provider) without the permission of software copyright owner, which enables users to access to software at their selected locations and time. This behavior violates the information network dissemination rights of computer software copyright owners. This paper analyses the transfer of tangible carrier of work that constitutes the lease right prescribed by copyright law. In the SaaS mode, Cloud users do not get the tangible copies of computer software. Therefore, application software supplied by cloud service providers to the cloud users is not subject to the rental right of software copyright owner. This result suggests that it's necessary to apply our ideas to finding a solution.
\end{abstract}

Keywords-SaaS mode of Cloud computing; Copyright; Rental right; Information network dissemination right

\section{INTRODUCTION}

SaaS business model of cloud computing brings the risk of infringement on software copyright owners. An example can be cited here that a cloud service provider uploads the application software to the "cloud" and provides these softwares to users without the permission from the software copyright owner. It is an unresolved question--which kinds of copyright owner's rights that this act shall subject to.

\section{COMMERCIAL MODEL AND TECHNICAL CHARACTERISTICS OF} SAAS

In a traditional network environment, internet users have to install the software with the assistance of CD or download it from the Internet. Whether it's a CD-ROM or a direct download from the Internet, it's all about making copies of the software in a hard disk on user's computer. However, in a cloud computing (software as a service) mode, cloud service providers install the software in the "cloud" (the remote server or data center), which is completely under the control of cloud service providers [1]; Cloud users do not need to store or install any software in their computers, instead they may command the cloud server and access to the "cloud" software at any time.

The most distinctive difference between the SaaS model and the traditional software licenses mode is that the cloud service provider does not provide an independent copy of software product to the user [2]. Cloud users can use the software and its function [3] by connecting to any browser in the cloud, but their acts will not form a permanent copy of the software in the user's computer [4].

\section{THE ANALYZE ON RENTAL RIGHTS APPLIED TO CLOUD SERVICE PROVIDERS IN SAAS MODE}

There is a view that cloud users in the SaaS model acquires "temporary use" of the software instead of copies for permanent use, which is similar with the functional temporary use of lessee for the rental. Also, Article 10 of the Copyright Law of the People's Republic of China stipulates that the right to rental refers to temporary use of the work, and it does not emphasize the transfer of the work carriers or copies [5]. Through proper expansion of lease rights application, it can be applied to the works dissemination under the SaaS mode [6]. Therefore, the lease right can regulate the behaviors of the cloud service providers who provide the software service under the SaaS model [7].

Article 11[8] of Trade-related Intellectual Property Agreement (TRIPs) and Article 7[9] of the Copyright Treaty of the World Intellectual Property Organization (WCT) defined the acts regulated by the lease right are the rental of the original or duplicate version of work instead of the work itself. Therefore only the possession transfer of a tangible carrier (original or duplicate) of a work constitutes the act of rental in copyright law.

Uploading a work to a computer server shall be defined as replication,-as it would form a permanent copy of the work in the server's hard disk [10]. The server's hard disk would serve as a tangible carrier of computer software, namely the copy of the software, after uploading the software to the "cloud" by cloud service providers. When providing software use services, cloud service providers do not need to transfer software copy to cloud users. Cloud users may access to the software through Internet. Therefore, there is distinctive difference between providing software to the public through the network transmission and the software leasing.

In 2011, a movie player and online streaming service called Zediva was appeared in the United States. The Zediva movie service provided by the defendant played movie DVDs online in accordance with customer's request after they purchased them legally. The defendant argues that renting those DVDs to customers does not need to obtain public performance license from the copyright owner of the movies. The district court of California, USA decided that the defendant's streaming service was to play the purchased movie DVDs, rather than rent them to customers. This behavior is what the American Copyright Law defines as on-demand public performance [11]. Although this case was about films but not computer software, it confirms the statement of Article 7 of WCT's: it is impossible 
to apply the right of lease of Article 7 for online transmission, as the right to rental only includes the act of putting tangible objects into circulation [12].

The role of transfer of the carriers or copies of the work in the right to rental has not been emphasized in Copyright Law of the People's Republic of China. However, in terms of jurisprudence, the right to rental merely refers to renting the tangible carrier of the work. The right to rental is based on the existence of a tangible copy of the work. In the SaaS mode, the cloud user does not own permanent copy of computer software, so it does not involve the right to rental. In the SaaS mode, cloud service providers upload the application software to the "cloud" without the permission of the software copyright owners, which is not regulated by the lease rights.

\section{THE ANALYSIS ON THE APPLICATION OF INFORMATION NETWORK DISSEMINATION RIGHT TO CLOUD SERVICE PROVIDERS UNDER THE SAAS MODE.}

The provisions of China's Copyright Law on the communication of information network refer to "the right of making available to the public" [13] in the second half of the Article 8 of the World Intellectual Property Organization (WCT) of [14]. In accordance with the Section 12, first paragraph of Article 10 of China's Copyright Law, the right of communication of information on networks refers to the right to communicate a work to the public, by wire or wireless means, ensuring that members of the public may access these works from a place and at a time individually chosen by themselves.

The behavior of information network communication can be characterized as follows:

\section{A. The communicator is the behavior subject of dissemination}

Those who only provide the means of communication do not commit an act of spreading information to the public, and those who can get in touch with the works do not commit any infringement upon the rights of dissemination. Those who upload the work to the server are the behavior subjects of the act of communicating information [15]. The guiding opinions from Beijing Higher People's Court considered that the judging standard that whether a service provider constituting behavior of communicating information through network is that whether a recording video, performance or recording video products been uploaded by a network service provider to the web server opening to the public [16].

\section{B. Provide works that are broadcasted to the public through network.}

In accordance with the Article 8 of the WCT, the act places the work on the information network by uploading it to a network server, setting up a shared file or using a file sharing software, etc., so that members of the public can visit the server at their personal-selected location and time, which constitutes the act of providing work to the public-by access to the work [17]. For the act of providing work to the public, Article 8 does not necessarily require a member of the public to send a download instruction or actually receive the work. It only emphasizes that the work is in an accessible state and it is possible for the public to access to them. Whether the public members actually get the work is not necessarily linked to the act of providers committing the act of information dissemination through network [18].

\section{An interactive and on-demand behavior.}

The dissemination of information network makes it available in such a way that members of the public may access these works from a place and at a time individually chosen by themselves, rather than passively accepting the spread or broadcast of the works. Although it is the communicator who uploaded the work to the server, the transmission was triggered directly by the uses. Only when public users access to the server, the content of the work would be transferred from the communicator's server to computers of specific users. As the constitutive elements, users could access to the works at any location or time they chose, which illustrates the interactive characteristics of "on-demanded access" [19].

From the features of software services provided by SaaS mode, cloud service provider uploads the application software to the cloud allowing a licensed cloud user to access to the remote server and to use a specific licensed software from a place and at a time individually chosen by the user. In the SaaS mode, cloud users can also access to the remote server and login, operate and use an application software by the Internet, from a place and at a time individually chosen by them.

Cloud service users use software through the Internet while the software code is transmitted from the Internet to the user's computer. The permanent copy of the used software would not be stored in users' computer terminals, which means that the cloud users would not own the software or its permanent copies. In a traditional mode, users may obtain a copy of the software by downloading it. Therefore, it is necessary to make clear that whether the situation where cloud service users only use and run the software without copying them will meet the requirements of ensuring people "access to work" prescribed in information network communication rights. 
Therefore, there are two unresolved issues related to the access to software.

\section{1) Whether access work need to download to obtain copies} of software

The definition of the right of dissemination of information networks stipulated in China's Copyright Law is derived from the text of Article 8 of WCT. The Chinese text, “获得作品” translated as "access to the work" in English version. In fact, the word "access" can be generally recognized as "obtain", but it includes the meanings of "contact, access, browsing".[20] Article 8 stipulates that members of the public may access these works by downloading, browsing or other means, rather than by downloading to obtain a temporary or permanent copy of the work [21].

In the case of Universal Records Corporation v. Shanghai Senlan Computer Network Co., Ltd., the court decided that the elements of committing the infringement upon rights of disseminating information through network do not necessarily require the public to download the works (produce a copy of the work). Whether a song can be downloaded or not, as long as the members of the public can enjoy and listen to the songs of the recording products at the time and place of their own choice, the act can be considered as accessing to a recording product. In the case of Chen Shaohua v. the Chinese Music Copyright Association [22], the court also decided that the elements of committing infringement on the rights of broadcasting through network do not necessarily require the public to download works. As long as the public could be able to perceive the work by watching, listening or other similar ways, it will lead to infringement.

In the second paragraph of Article 2 of Guiding Opinions on Copyright Disputes in the Network Environment (1) (for Trial Implementation) (2010), the Higher People's Court of Beijing also considered that the access to works regulated in information network communication rights includes acts of downloading, browsing, etc., "Access" shall not only be defined as "download".

2) Whether online use or the operation of software shall be defined as accessing to works

There is a view that computer software can be recognized as "works" as well as "tools". Cloud services users use software in the SaaS mode to obtain "functions" of software instead of the "content", what cloud service users acquired is the application of the works, and it shall not be defined as "access to the work" [23]. The nature of acts of downloading a software, online browsing and download non-software works are similar, as well as their impacts on the economic interests of copyright owners. Therefore, only when the cloud services users download and obtain copies of the software, can their acts be considered as "access to the work" [24].

However, there are some differences between computer software and other written works. The main value of computer software comes from the application of software programs, which is named by functional work. The reason why computer software can be protected by copyright law is based on the specific instructions and code used to express design thought. However, its instructions and code cannot reflect the emotion or beauty expressed by traditional works.

The purpose of designing a computer software is to achieve certain functions. The computer software users may achieve their specific purpose by running the software and using its functions [25]. Computer software users do not need to understand or perceive the instructions and code of the software program, instead, they only need to know and obtain output data, and results after the operation [26]. The purpose of accessing to a computer software is not to feel the sense of beauty or the thought and emotion expressed by a program's instruction and code, rather, it is to obtain the result by running the software.

Running software online or running the software after downloading it would both affect the economic interests of the copyright owner. That the software copyright owners control and limit on-line use of the software is designed to protect their economic benefits. Therefore, "access" to works shall include the act of using the value of works, such as reading literature, watching film and television, and as well as running computer software [27]. The acts of members of the public contacting works online, such as online reading, listening, watching works and running antivirus software, shall be defined as obtaining works [28].

In the Chamberlain v. Sky link case heard by the Federal Circuit of the United States, the universal remote controller sold by the defendant to his customers could evade the antitheft code so that to access the plaintiff's copyrighted software and run the opening and closing system of the plaintiff's garage door. Therefore, the company was accused of selling equipment for avoiding the access control measures set on the plaintiff's software. [29]Clearly, the Federal Circuit Court of the United States considered that the meaning of access to computer software included the use and operation of software.

Article 68 of the Copyright Law of the People's Republic of China (Revised Draft for Ratification) promulgated on June 6, 2014 stipulates that technical protection measures refer to effective technologies, devices or components taken by copyright owners to prevent or limit the reproduction, browsing, appreciation, operation, adaptation or dissemination of their works by the means of performances, sound recordings or radio and television programs. "Browsing, appreciating, operating" are the acts of contacting works and other copyright objects, and the "running" obviously indicates the "contact" of the software works.

This demonstrates that the online operation and the use of software shall be included as "access to, contact the work" under the definition of rights to communicate information through network.

The characteristic of the act providing information regulated by the right of disseminating information through network is that it ensures the members of the public to "access the work" interactively on their demands. In the SaaS mode, cloud service providers install the software in the "cloud" (the remote server or data center) so that members of the public may access works from a place and at a time individually 
chosen by themselves, which should be regulated by the right of broadcasting information through network. If cloud service providers upload application software to the "cloud" without the permission of the software copyright owners, their acts will violate the information dissemination right of copyright owners of computer software.

\section{CONCLUSION}

The possession transfer of the tangible carriers of the works constitutes the lease in copyright law, and the right of rental is based on the existence of the tangible copies of the works. In the SaaS mode, cloud service users do not obtain the permanent copy of the computer software. Therefore, the act that cloud service providers upload the application software to "cloud" without permission of the software copyright owner and provide to cloud users is not subject to the regulation of the lease rights of the software copyright owners.

Online operation and use of software are included as accessing to works under the definition of rights of information dissemination through network. In the SaaS mode, the behavior of the cloud service providers is subject to the regulation of rights of information dissemination through network. If cloud service providers upload application software to the "cloud" without permission of the software copyright owner, their acts may violate the right of information dissemination through network owned by computer software copyright owners.

\section{REFERENCES}

[1] Alexander Savelyev: Software-as-a-Service-Legal Nature: Shifting the Existing Paradigm of Copyright Law, Computer Law \& Security Review, 2014(30), P561.

[2] Gao Fuping: The Legal Problems of Cloud Cmputing and its Countermeasures, Law, 2012(6), P 7.

[3] George Jiang: Rain or Shine: Fair and Other Non-infringing Uses in the Context of Cloud Computing, University of Notre Dame Journal of Legislation, 2010, P414.

[4] Luo Xianjue, Yin Fenglin: The Influence of Cloud Computing on the Protection of Intellectual Property. Intellectual Property, 2012(4), P61.

[5] The right to rental is a temporary use of the film works and the right to produce the works and computer software, and the computer software is not the main subject of rental.

[6] Liang zhiwen: Cloud Computing, Technology Neutrality and Copyright Responsibility, Law, 2011(3),P95

[7] Bao Zhengye: An Analysis of the Problem of Cloud Computing Copyright--in the Case of the SaaS Model, Jinan Journal (Philosophy and Social Sciences), 2013(4), P11.
[8] Members shall allow the author and heir of the computer program and the work of the film to allow or prohibit the right to lease of the original or copy to the public.

[9] The author of the computer program and the film works has the right to lease the original or copy of its work to the public.

[10] Wang Qian, the Identification of Copyright Direct Infringement under the Network Environment, Oriental Law 2009(2), P17.

[11] Warner Bros. Entm't Inc. v. WTV Sys. Inc.,824 F. Supp. 2d 100508(C.D.Cal.2011)

[12] JorgReinbothe, Silke Von Lewinski, the WIPO Treaties 1996, P105.

[13] Making available to the public of their works in such a way that members of the public may access these works from a place and at a time individually chosen by them.

[14] Guo Shoukang, Wan Yong: A Review of the Protection of Information Network and the Protection. Electronic Intellectual Property, 2006(10).

[15] Liang zhiwen: Digital Copyright Theory, Intellectual Property Press, 2007, P28.

[16] Beijing Higher People's Court "On the Hearing of A Number of Issues Relating to Copyright Disputes under the Network Environment (1) (2010), No.4, Section 1.

[17] Wan Yong: The Right to spread to the Public, Legal publishing, 2014, P149.

[18] Andrew Christie, Eloise Dias, the New Rights of Communication in Australia, Sydney Law Review, 2005, P248.

[19] Jorge. Reinberg, Sylke. Fon. Levinski: WIPO Internet Treaty Commentary. Translation: Wan Yong, Xiang jing, China people's University Press, 2008, P136.

[20] Wang Qian: The Identification of Copyright Direct Infringement under the Network Environment, Oriental Law, 2009(2), p17.

[21] Cui Guobin: The Principle and Case of Copyright Law, Peking University Press, 2014, P487.

[22] Wuhan Intermediate People's Court, Hubei province (Intellectual Property) No.179.

[23] Liangzhiwen: "Cloud Computing, Technology Neutrality and Copyright Responsibility", Law, 2011(3).

[24] Bao Zhengye: An analysis of the Problem of Cloud Computing copyright--in the Case of the SaaS Model, Jinan Journal (Philosophy and Social Sciences), 2013(4), P11.

[25] Liang Zhiwen: "Digital Copyright Theory," Intellectual Property Press, 2007, P28.

[26] He Lianhong: The Theory of Copyright Protection of Functional Works and the Power of Solving the Path habit", "Modern Law" 2005(5), P107.

[27] Liu Ying: The Scope of Technical Measures on Copyright Law, Law Review, 2017 (3), P101.

[28] Wang Qian: Network Copyright Law, China People's University Press, 2008, P69.

[29] Chamberlain Group, Inc. v. Skylink Technologies, Inc., 381 F.3d 1186 (Fed. Cir. 2004). 